\title{
Targeted therapy in triple-negative metastatic breast cancer: a systematic review and meta-analysis
}

This article was published in the following Dove Press journal:

Core Evidence

6 January 2014

Number of times this article has been viewed

\author{
Otávio Clark' \\ Tobias Engel Ayer Botrel' \\ Luciano Paladini' \\ Mariana Bhering Andrade \\ Ferreira $^{2}$ \\ 'Evidências Consulting, Campinas, \\ Brazil; ${ }^{2}$ Roche do Brasil, São Paulo, \\ Brazil
}

Objective: To perform a systematic review and meta-analysis of randomized controlled trials that compared the efficacy of targeted therapy to conventional chemotherapy (CT) in patients with metastatic triple-negative breast cancer (TNBC).

Methods: Several databases were searched, including Medline, Embase, LILACS, and CENTRAL. The primary end point was progression-free survival (PFS). We performed a metaanalysis of the published data. The results are expressed as hazard ratio (HR) or risk ratio, with their corresponding 95\% confidence intervals (95\% CIs).

Results: The final analysis included twelve trials comprising 2,054 patients with TNBC, which compared conventional CT alone against CT combined with targeted therapy (bevacizumab [Bev], sorafenib [Sor], cetuximab, lapatinib, and iniparib). PFS was superior in previously untreated patients with TNBC who received Bev plus CT compared to CT alone (fixed effect, HR 0.62, 95\% CI $0.51-0.75 ; P<0.00001)$. Also, PFS was higher in one study that tested Bev plus CT combination in previously treated patients (HR $0.49,95 \%$ CI $0.33-0.74 ; P=0.0006$ ). Sor plus CT was also tested as first-line and second-line treatments. The pooled data of PFS favored the combination CT plus Sor (fixed effect, HR 0.69, 95\% CI 0.49-0.98; $P=0.04$ ). Comparisons of iniparib plus CT also had a better PFS than CT alone (fixed effect, HR 0.75, 95\% CI 0.62-0.90; $P=0.002$ ).

Conclusion: Targeted therapy, when associated with conventional CT, demonstrated gains in the PFS of patients with TNBC.

Keywords: triple-negative, chemotherapy, breast cancer, systematic review

Core evidence clinical impact summary for targeted therapy in triple-negative metastatic breast cancer

\begin{tabular}{|c|c|c|}
\hline Outcome measure & Evidence & Implications \\
\hline Disease-oriented evidence & $\begin{array}{l}\text { Iniparib or cetuximab when associated } \\
\text { with the conventional chemotherapy, } \\
\text { demonstrated gains in the response } \\
\text { rate. }\end{array}$ & $\begin{array}{l}\text { The overall response rate } \\
\text { was higher in patients who } \\
\text { received the combination } \\
\text { of chemotherapy plus } \\
\text { iniparib or cetuximab. }\end{array}$ \\
\hline Patient-oriented evidence & $\begin{array}{l}\text { Bevacizumab, sorafenib and iniparib } \\
\text { plus conventional chemotherapy, } \\
\text { showed superiority in the } \\
\text { progression-free survival of patients } \\
\text { with triple-negative breast cancer. }\end{array}$ & $\begin{array}{l}\text { A significant benefit was } \\
\text { found in the progression- } \\
\text { free survival using } \\
\text { conventional chemotherapy } \\
\text { associated with targeted } \\
\text { therapy (bevacizumab, or } \\
\text { sorafenib and iniparib). }\end{array}$ \\
\hline Economic evidence & $\begin{array}{l}\text { Neither a cost effectiveness nor } \\
\text { a budgetary impact analysis were } \\
\text { performed }\end{array}$ & $\begin{array}{l}\text { Neither a cost effectiveness } \\
\text { nor a budgetary impact } \\
\text { analysis were performed }\end{array}$ \\
\hline
\end{tabular}

Correspondence: Otávio Clark Evidências Consulting, I 43 Tranquillo Prosperi, Campinas, São Paulo 13084-778, Brazil

Tel +5519981495375

Fax +551932878310

Email otavio.clark@evidencias.com.br submit your manuscript | www.dovepress.com

Dovepress

http://dx.doi.org//0.2147/CE.S52197
Core Evidence 2014:9 I-II

(c) (1) (2) $\odot 2014$ Clark et al. This work is published by Dove Medical Press Limited, and licensed under Creative Commons Attribution - Non Commercial (unported, v3.0)

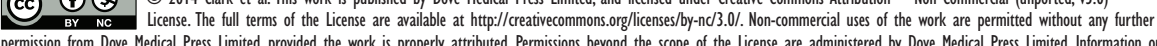
permission from Dove Medical Press Limited, provided the work is properly attributed. Permissions beyond the scope of the License are administered by Dove Medical Press Limited. Information on how to request permisision may be found at. http://www.dovepress.com/permissions.php 


\section{Introduction}

Metastatic breast cancer is generally considered an incurable malignancy. ${ }^{1}$ The primary goals of treatment have been palliation and disease control, with some therapies providing a limited survival benefit. ${ }^{1}$

Around $10 \%-17 \%$ of breast cancers are defined as triplenegative $(\mathrm{TN})$, ie, absence of estrogen receptor, progesterone receptor, and of overexpression and/or amplification of the HER2/ $N E U$ gene..$^{2-8}$ These tumors have some similarities with those known as basal-like tumors, since both affect young patients $(<50$ years old) and have a higher prevalence in women of African descent, besides being significantly more aggressive, with higher risk of systemic recurrence and death than other breast tumors. ${ }^{3,4,910}$ The peak risk of recurrence of these tumors happens between the first and third years after diagnosis, and most deaths occur within the first 5 years after therapy starts., ${ }^{3,8,11}$

The finding that BRCA1 mutations are present in a substantial proportion $(25 \%)$ of patients with TN breast cancer (TNBC) and the similarities of these tumors with the basal-like subtype suggest that the therapeutic approach can be shared between these tumors. ${ }^{4,12,13}$ Preclinical studies have shown that these tumors are sensitive to alkylating agents, such as mitomycin $\mathrm{C}$ and platinum analogues (cisplatin and carboplatin). ${ }^{14,15}$

Currently, cytotoxic chemotherapy (CT) is the only option of treatment for metastatic TNBC. Women with TNBC do not seem to benefit from endocrine therapy or trastuzumab. ${ }^{14}$ Some molecular-targeted therapies have demonstrated efficacy in this subgroup of patients. ${ }^{16,17}$ Bevacizumab (Bev), a monoclonal antibody against vascular endothelial growth factor, used in association with conventional $\mathrm{CT}$ was evaluated in randomized studies that included TNBC patients. Results for this subgroup showed a benefit for this medication. ${ }^{16,17}$ Other examples of drugs with potential benefit for TNBC are cetuximab (epidermal growth-factor receptor inhibition) ${ }^{18}$ and poly(adenosine diphosphate-ribose) polymerase (PARP) inhibition. ${ }^{19}$

Due to the lack of specific information, there are no published evidence-based clinical guidelines with explicit recommendations about which systemic treatment scheme is more appropriate for these patients with advanced TNBC., ${ }^{911}$ The clinical impact of molecular-targeted therapy in the TN population is still not clear. ${ }^{20}$ Most information about TN patients comes from subgroup analyses of larger trials, and to our knowledge no systematic synthesis of the studies has been performed so far.

The objective of this study was to perform a systematic review of the literature, with a meta-analysis of randomized studies that evaluated the targeted therapies with conventional $\mathrm{CT}$ versus conventional $\mathrm{CT}$ alone in patients with TNBC (or basal-like tumor).

\section{Methods}

\section{Study-selection criteria}

Types of studies

Randomized prospective studies that compared targeted therapy combined with conventional $\mathrm{CT}$ versus conventional CT alone in patients with TNBC (or basal-like tumor) were included. We included studies that specifically evaluated this population or those in which a separate analysis for the TNBC patients was performed.

\section{Types of participants}

The selected studies included patients with metastatic TNBC.

\section{Search strategy for identification of studies}

A broad search on the main computerized databases was conducted, including Embase, LILACS, Medline, Science Citation Index (SCI), CENTRAL, the National Cancer Institute Clinical Trials Service, and the Clinical Trials Register. In addition, the annual meeting proceedings of the American Society of Clinical Oncology, the San Antonio Breast Cancer Symposium, the American Association for Cancer Research, and the European Society for Medical Oncology were searched. The manufacturer of Bev in Brazil (Roche) was consulted about ongoing studies that had not yet been published or identified.

The search-strategy methodology for randomized controlled trials ${ }^{21}$ recommended by the Cochrane Collaboration ${ }^{22}$ was used for Medline. We used an adaptation of this same strategy $^{21}$ for Embase, and for LILACS we applied the search-strategy methodology reported by Castro et al. ${ }^{23} \mathrm{An}$ additional search was performed on the SCI database looking for articles that were cited in the included studies. We added the specific terms pertinent to this review to the overall search-strategy methodology for each database.

The overall search strategy was: 1) "breast neoplasms," 2) "triple negative," 3) "chemotherapy," and 4) randomized controlled trial. Searches in electronic databases combined terms $1-4$.

If the data regarding the $\mathrm{TN}$ population were not available in the original report, we searched many secondary sources and tried to contact the authors of those studies in order to obtain the information.

\section{Critical evaluation of the selected studies}

All references retrieved by the search strategies had their title and abstract evaluated by two of the researchers. Every reference with the least indication of fulfilling the inclusion criteria 
was listed as preselected. We retrieved the complete articles of all preselected references. They were analyzed by two different researchers and included or excluded according to the previously reported criteria. Excluded trials and the reason for their exclusion were listed and checked by a third reviewer. Two reviewers read the included studies, and all data of interest were extracted using a standard formulary. If the TNBC analysis was not reported in the original paper, we looked for it in many different sources, such as secondary publications, meeting publications, and direct contact with authors, among others.

Details regarding the main methodology characteristics empirically linked to bias ${ }^{24}$ were extracted, and the methodological validity of each selected trial was assessed by two reviewers (TEAB and OC). Particular attention was given to some items: the generation and concealment of the sequence of randomization; blinding; application of intention-to-treat analysis; sample size predefinition; adverse-event reports; if the trial was multicentric or unicentric; and the sponsorship.

\section{Data extraction}

Two independent reviewers extracted the data. The name of the first author and the year of publication were used to identify the study. All data were extracted directly from the text or calculated from the available information when necessary. The data on all trials were based on the intentionto-treat principle, so they compared all patients allocated to one treatment with all those allocated to the other.

The primary end point was progression-free survival (PFS). Progression was defined as development of new lesions or "unequivocal progression" of existing lesions, as defined by the original researchers. Secondary end points included objective response rate, overall survival (OS), and adverse events (grade $\geq 3$ ).

Adverse events analyzed were: neutropenia, thrombocytopenia, anemia, febrile neutropenia (hematological); and fatigue, nausea, thromboembolic events, vomiting, rash, left ventricular dysfunction, hand/foot skin reaction, allergic reaction, proteinuria, hypertension, mucositis, neuropathy, headache, bleeding events, and gastrointestinal perforation (nonhematological).

\section{Analysis and presentation of results}

The data were analyzed using the Review Manager 5.0.24 statistical package (Cochrane Collaboration, Oxford, UK). ${ }^{25}$ Dichotomous clinical outcomes are reported as risk ratios (RRs) and survival data as hazard ratios (HRs). ${ }^{26}$ The corresponding 95\% confidence intervals (95\% CIs) were calculated, and a significant $P$-value was considered to be less than $5 \%(P<0.05)$. Statistical heterogeneity was calculated through the $I^{2}$ method $(25 \%$ was considered low-level heterogeneity, 25\%-50\% moderate-level heterogeneity, and $>50 \%$ high-level heterogeneity). ${ }^{27,28}$

If time-to-event data were not available in the study's reports, they were then indirectly estimated, using the methods described by Parmar et al. ${ }^{26}$ A pooled estimate of the HR was computed by a fixed-effect model according to the inversevariance method..$^{29}$ Thus, for effectiveness or side effects, an HR or RR greater than 1 favors the standard arm (conventional CT), whereas an HR or RR less than 1 favors the experimental treatment (targeted therapy with CT).

If a high level of statistical heterogeneity was found in the meta-analysis, an additional analysis was performed using the random-effects model described by DerSimonian and Laird, ${ }^{30}$ which provides a more conservative analysis.

To assess the possibility of publication bias, the funnel-plot test described by Egger et al was performed. ${ }^{31}$ When the pooled results were significant, the number of patients needed to treat to benefit one (NNT) was calculated by pooling absolute-risk differences in the trials included in this meta-analysis. ${ }^{32-34}$ For all analysis, a forest plot was generated to display results.

\section{Results}

Figure 1 represents the flow of identification and inclusion of trials, as recommended by the PRISMA (Preferred Reporting Items for Systematic reviews and Meta-Analysis) statement. ${ }^{35}$ In the first search, 215 articles were obtained. Thirty-two studies were selected and retrieved for full-text analysis. Of these studies, 20 were excluded for various reasons, described in Table 1.

The final analysis included twelve trials comprising 2,048 patients. The targeted therapies studied were Bev, sorafenib (Sor), cetuximab, lapatinib, and PARP inhibitors. Some of the included studies ${ }^{18,36,37}$ did not report the TNBC subgroup analysis in the original article, and this information was obtained at conference presentations and/or other subsequent publications (Table 2). A quality assessment of the included studies is shown in Table 3. According to the funnel-plot ${ }^{31}$ analysis, the possibility of publication bias was low for all end points.

\section{Chemotherapy with bevacizumab}

Four studies evaluated Bev plus CT versus CT alone: three in first-line ${ }^{16,17,38-40}$ and one in second-line therapy. ${ }^{41-42}$ Most of the studies used a dose of Bev of $15 \mathrm{mg} / \mathrm{kg}$ every 3 weeks or $10 \mathrm{mg} / \mathrm{kg}$ every 2 weeks, depending on the chemotherapy regimen. One three-arm study (AVADO) ${ }^{16}$ evaluated Bev at two different doses: one group received Bev $7.5 \mathrm{mg} / \mathrm{kg}$ and another $15 \mathrm{mg} / \mathrm{kg}$. We used the $15 \mathrm{mg} / \mathrm{kg}$ results to perform this meta-analysis. 


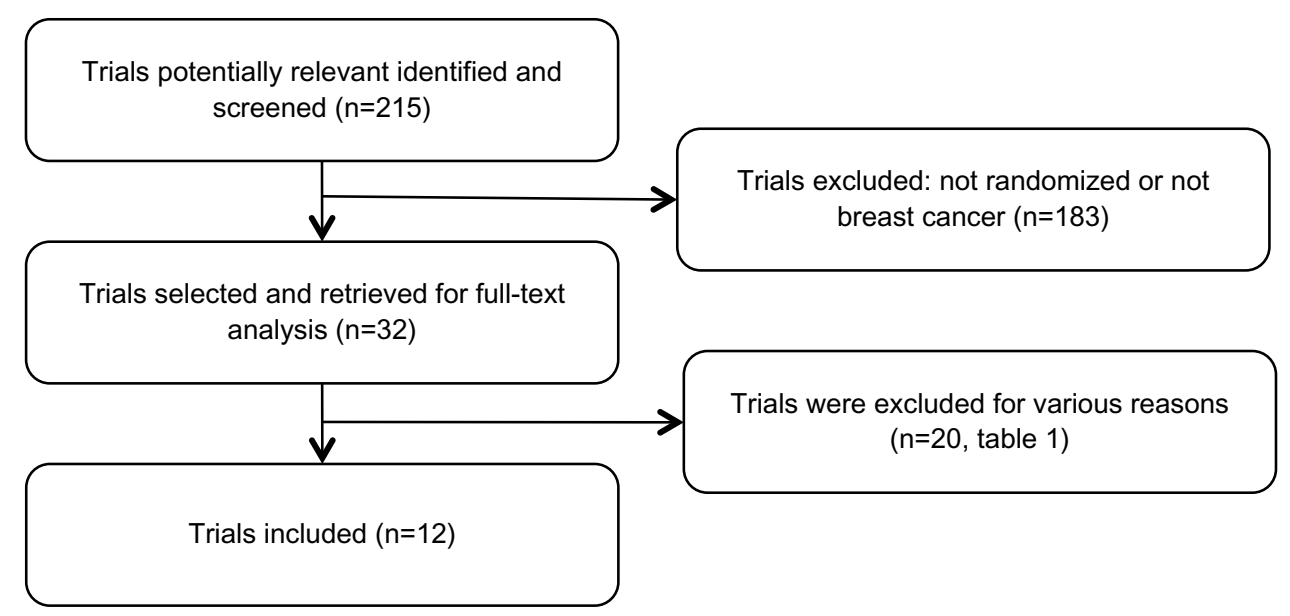

Figure I Trial-selection flow.

Bev was combined with many different $\mathrm{CT}$ regimens (paclitaxel, docetaxel, capecitabine, anthracyclines, gemcitabine, and vinorelbine). The results showed a superior PFS in patients who received Bev plus CT compared to CT alone in previously untreated TNBC (fixed effect, $\mathrm{HR}=0.62$; 95\% CI 0.51-0.75; $P<0.00001 ; \mathrm{NNT}=2$ ) with no significant heterogeneity $\left(\chi^{2}=4.01\right.$, degrees of freedom $(d f)=3 ; P=0.26$;

Table I Characteristics of the excluded studies

\begin{tabular}{|c|c|}
\hline Study & Reasons for exclusion \\
\hline Chia $^{54}$ & $\begin{array}{l}\text { Metastatic TN subgroup but not } \\
\text { randomized }\end{array}$ \\
\hline Curigliano et $\mathrm{a}^{55}$ & Sunitinib versus $Q T$ in one arm \\
\hline Berry et $\mathrm{al}^{56}$ & $\begin{array}{l}\text { Stratified patients only by hormone } \\
\text { receptor }\end{array}$ \\
\hline Gluz et $\mathrm{al}^{57}$ & $\mathrm{CT}$ in high doses \\
\hline Rodenhuis et $\mathrm{al}^{58}$ & $\mathrm{CT}$ in high doses \\
\hline Silver et al ${ }^{59}$ & $\begin{array}{l}\text { Neoadjuvant TN subgroup and } \\
\text { nonrandomized }\end{array}$ \\
\hline Bonnefoi et $\mathrm{al}^{60}$ & $\begin{array}{l}\text { Stratified patients only by hormone } \\
\text { receptor }\end{array}$ \\
\hline Leone et $\mathrm{al}^{61}$ & Neoadjuvant $\mathrm{CT}$ and nonrandomized \\
\hline Torrisi et al ${ }^{62}$ & Neoadjuvant $\mathrm{CT}$ and nonrandomized \\
\hline Ryan et al ${ }^{63}$ & Neoadjuvant $\mathrm{CT}$ and nonrandomized \\
\hline Frasci et $\mathrm{al}^{64}$ & Neoadjuvant $\mathrm{CT}$ and nonrandomized \\
\hline Finn et $\mathrm{al}^{65}$ & $\begin{array}{l}\text { Metastatic TN subgroup and } \\
\text { nonrandomized }\end{array}$ \\
\hline Wang et $a^{166}$ & $\begin{array}{l}\text { Metastatic TN subgroup and } \\
\text { nonrandomized }\end{array}$ \\
\hline Citron et $\mathrm{a}^{\mathrm{l}^{67}}$ & $\begin{array}{l}\text { Stratified patients only by hormone } \\
\text { receptor }\end{array}$ \\
\hline Garber et $a^{68}$ & Neoadjuvant $\mathrm{CT}$ and nonrandomized \\
\hline Byrski et al ${ }^{69}$ & Neoadjuvant $\mathrm{CT}$ and nonrandomized \\
\hline von Minckwitz et al ${ }^{70}$ & $\begin{array}{l}\text { Stratified patients only by hormone } \\
\text { receptor }\end{array}$ \\
\hline Carey et $\mathrm{a}^{71}$ & Cetuximab in both groups \\
\hline Bhattacharrya et $\mathrm{al}^{72}$ & Not targeted therapy \\
\hline Rugo $^{73}$ & Not targeted therapy \\
\hline
\end{tabular}

Abbreviations: $\mathrm{TN}$, triple negative; $\mathrm{CT}$, chemotherapy.
$I^{2}=25 \%$ ) (Figure 2). These studies did not report either the response-rate data or the OS for the TN subgroup.

In the study that evaluated Bev plus CT in second-line therapy, PFS was also superior in the group that received Bev $(\mathrm{HR}=0.49,95 \%$ CI $0.33-0.74 ; P=0.0006) .{ }^{41,42} \mathrm{~A}$ nonsignificant, higher OS was seen for the TNBC patients that received Bev $(\mathrm{HR}=0.624,95 \% \mathrm{CI} 0.39-1.007)$ (Table 2$)$. The proportion of hematologic toxicities was similar between the group that received Bev plus CT compared to the one that received $\mathrm{CT}$ alone. Some nonhematologic toxicities reported were more frequent in patients who received Bev plus CT: proteinuria (fixed effect, $\mathrm{RR}=11.87,95 \%$ CI $3.41-41.32$; $P=0.0001$ ), hypertension (fixed effect, $\mathrm{RR}=13.72,95 \% \mathrm{CI}$ 6.93-27.15; $P<0.00001$ ), neuropathy (fixed effect, $\mathrm{RR}=1.40$, 95\% CI 1.09-1.79; $P=0.008$ ), and bleeding events (fixed effect, RR $=5.81,95 \%$ CI 1.87-18.01; $P=0.002$ ). The other nonhematologic toxicities were similar between the groups.

\section{Chemotherapy with sorafenib}

One study compared Sor plus CT versus CT in first-line treatment, ${ }^{37,43}$ and two in second-line treatment. ${ }^{1,36,44,45}$ In firstline treatment, Sor ( $400 \mathrm{mg}$, orally, twice daily) was associated with paclitaxel, and in second-line treatment Sor was associated with gemcitabine or with capecitabine (Table 2). The response rate was not reported for the TNBC subgroup.

PFS was superior for the group treated with Sor in secondline therapy (fixed effect, HR $=0.58,95 \%$ CI $0.36-0.93$; $P=0.02$; NNT $=2$ ). In the pooled overall analysis, PFS remained superior in the group that received Sor versus CT alone (fixed effect, $\mathrm{HR}=0.69,95 \%$ CI $0.49-0.98 ; P=0.04$ ), regardless of the treatment line (Figure 3). There was no heterogeneity in this analysis $\left(\chi^{2}=1.15, d f=2 ; P=0.56 ; P^{2}=0 \%\right)$. One study reported the OS data, and there was no difference between the groups. ${ }^{1,44,45}$ 
Table 2 Characteristics of the randomized studies that evaluated different schemes of chemotherapy only in the advanced TNBC (or "basal like" tumor) subgroup

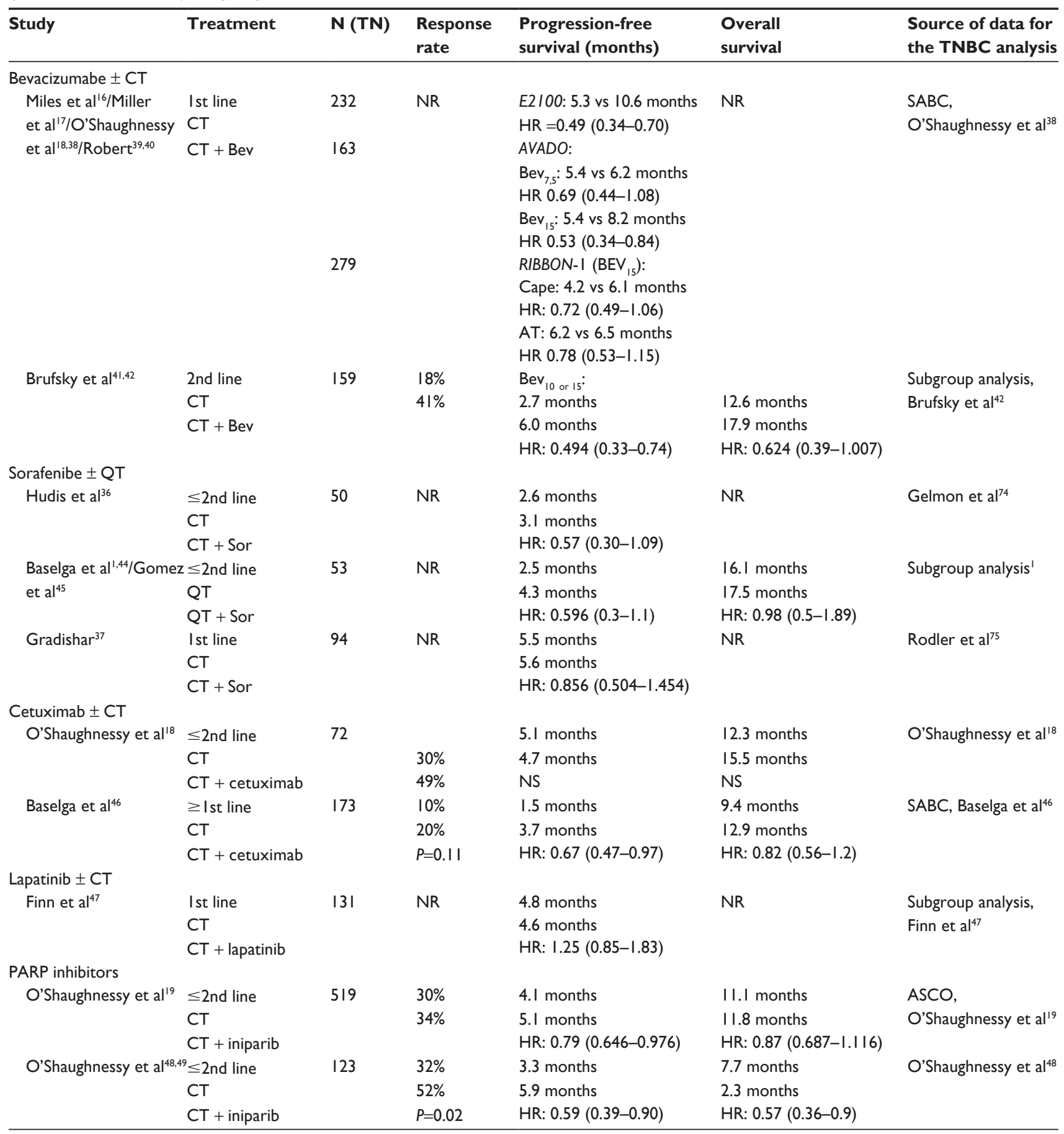

Abbreviations: CT, chemotherapy; PARP, poly(ADP-ribose) polymerase; Bev, bevacizumabe; Cape, capecitabina; AT, antracycline and taxane; HR, hazard ratio; SABC, San Antonio Breast Cancer Symposium; ASCO, American Society of Clinical Oncology; TN, triple negative; NS, not significant; BC, breast cancer; NR, not reported.

The proportion of hematologic toxicities was similar between the group that received Sor plus CT compared to the one that received CT alone. Hand/foot skin reaction and mucositis were more frequent in patients treated with Sor plus $\mathrm{CT}$ (hand/foot skin reaction fixed effect, $\mathrm{RR}=5.00,95 \%$ $\mathrm{CI}=3.30-7.58, P<0.00001$; mucositis fixed effect, $\mathrm{RR}=2.79$,
95\% CI 1.01-7.72, $P=0.05)$. The other nonhematologic toxicities were similar between the groups.

\section{Chemotherapy with cetuximab}

Cetuximab plus CT was studied in patients previously treated for metastatic disease in two randomized studies. Cetuximab 


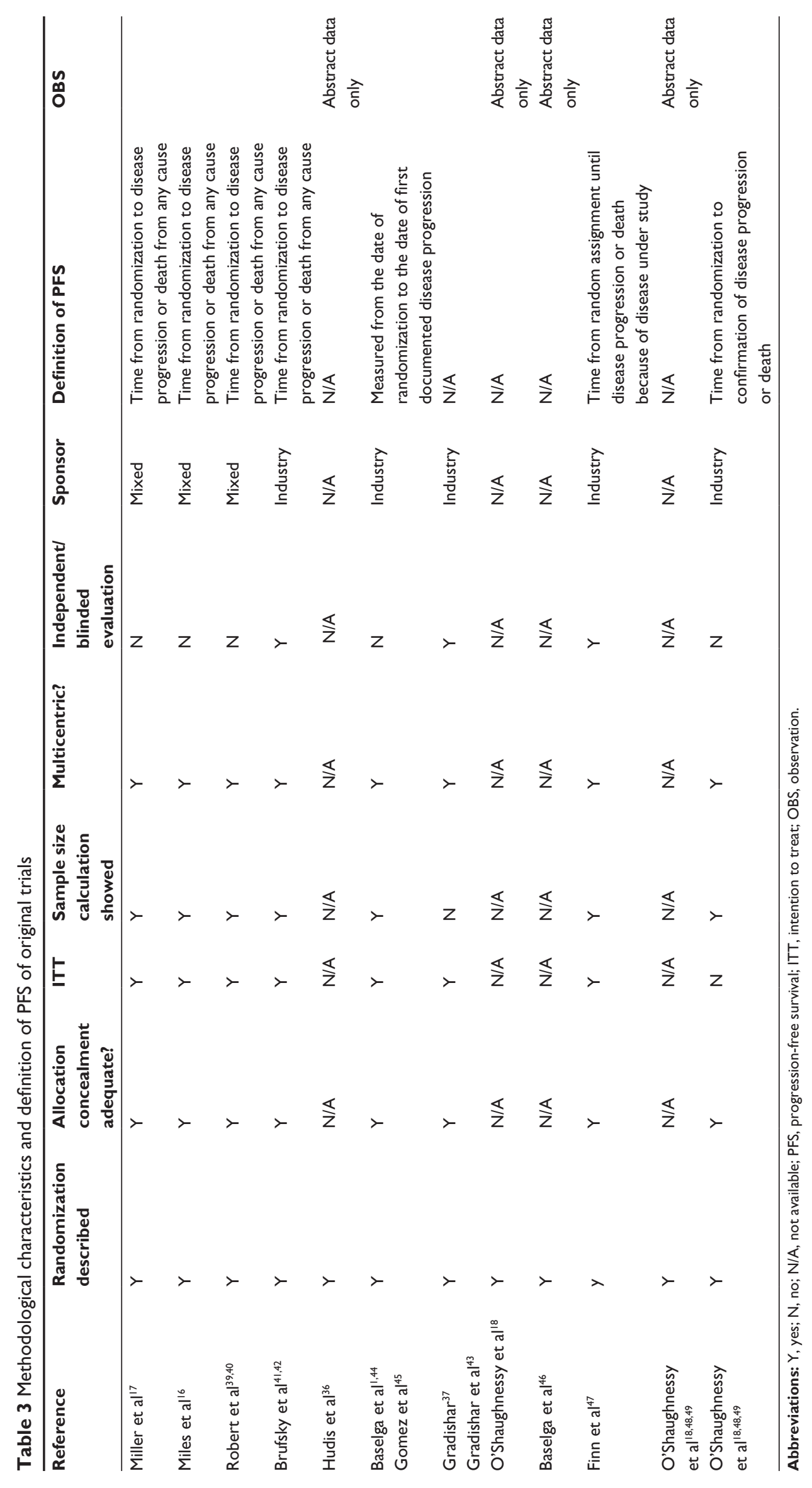




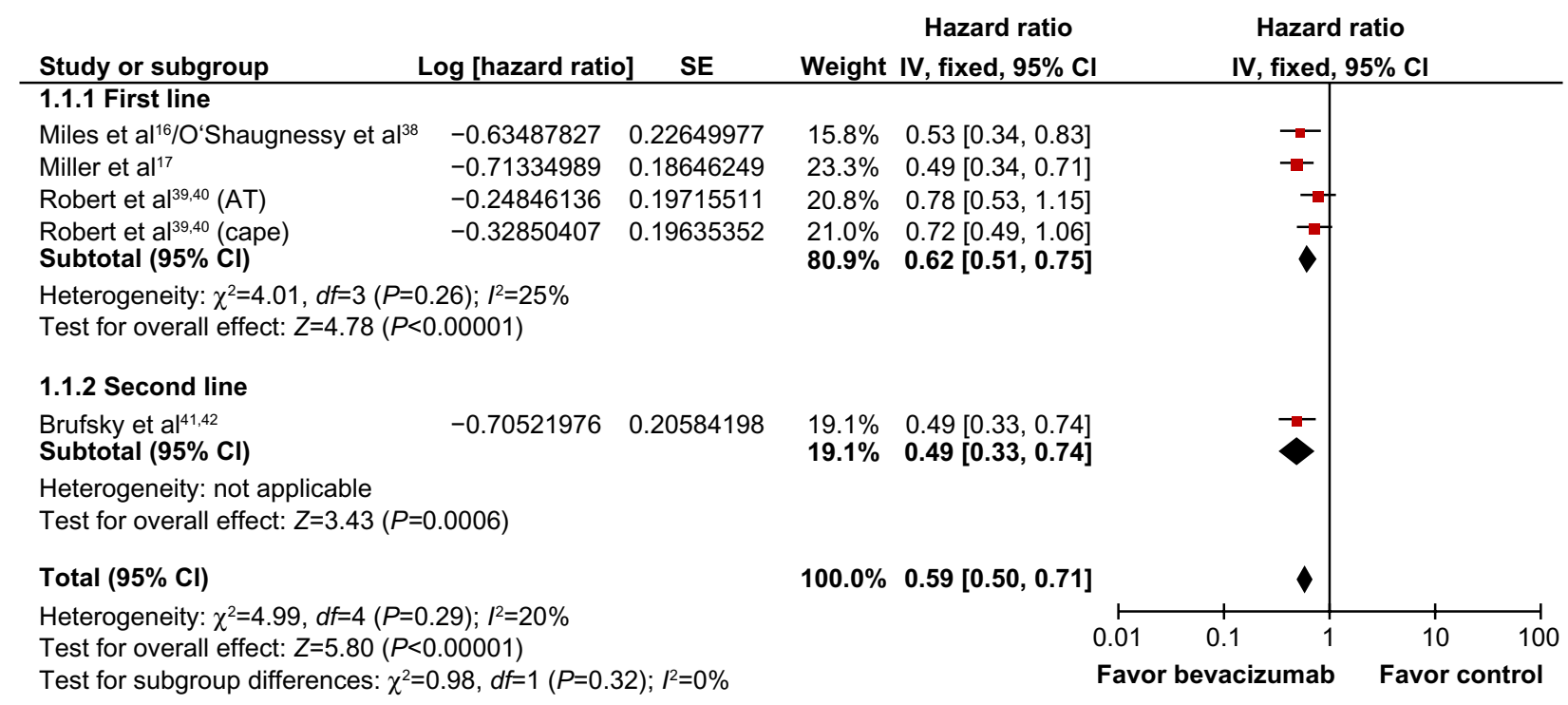

Figure 2 Comparative effect on progression-free survival of chemotherapy plus bevacizumab versus chemotherapy alone (fixed-effect model analysis). Abbreviations: SE, standard error; IV, inverse variance; cape, capecetabin; Cl, confidence interval; AT, antracycline and taxane; $d f$, degrees of freedom.

(400 mg/m² initial dose followed by $250 \mathrm{mg} / \mathrm{m}^{2}$ weekly) was combined with irinotecan and carboplatin in one study ${ }^{18}$ and with cisplatin in another study ${ }^{46}$ (Table 2).

The meta-analysis showed a higher response rate for the $\mathrm{CT}$ with cetuximab group versus $\mathrm{CT}$ alone (fixed effect, $\mathrm{RR}=0.85,95 \%$ CI $0.74-0.97 ; P=0.02)$. There was no heterogeneity in this analysis $\left(\chi^{2}=1.11, d f=1 ; P=0.29 ; I^{2}=10 \%\right)$. Only one study ${ }^{46}$ reported complete PFS and OS data for cetuximab. In this study, PFS was higher for the group of patients treated with cetuximab plus CT versus CT alone (HR $=0.67,95 \%$ CI $0.47-0.97)$; OS was similar between the groups ( $\mathrm{HR}=0.82,95 \% \mathrm{CI} 0.56-1.2)$. The other study ${ }^{18}$ was presented in a conference and did not report PFS or OS data. We contacted the author about these data, but received no answer. The available conference presentation reported medians and stated that there was no statistically significant difference between the groups in either the median PFS (5.1 months versus 4.7 months) or in the median OS (12.3 months versus 15.5 months).

Neutropenia and rash were more frequent in patients who received cetuximab plus $\mathrm{CT}$ compared to those that received $\mathrm{CT}$ alone (neutropenia fixed effect, $\mathrm{RR}=1.85,95 \%$ CI 1.36-2.52, $P<0.0001$; rash fixed effect, $\mathrm{RR}=16.64,95 \%$ CI 1.02-272.53, $P=0.05$ ). The other toxicities were similar between the groups.

\section{Chemotherapy with lapatinib}

We found only one study evaluating CT plus lapatinib $(1,500 \mathrm{mg} \text { orally daily })^{47}$ versus conventional CT (paclitaxel)

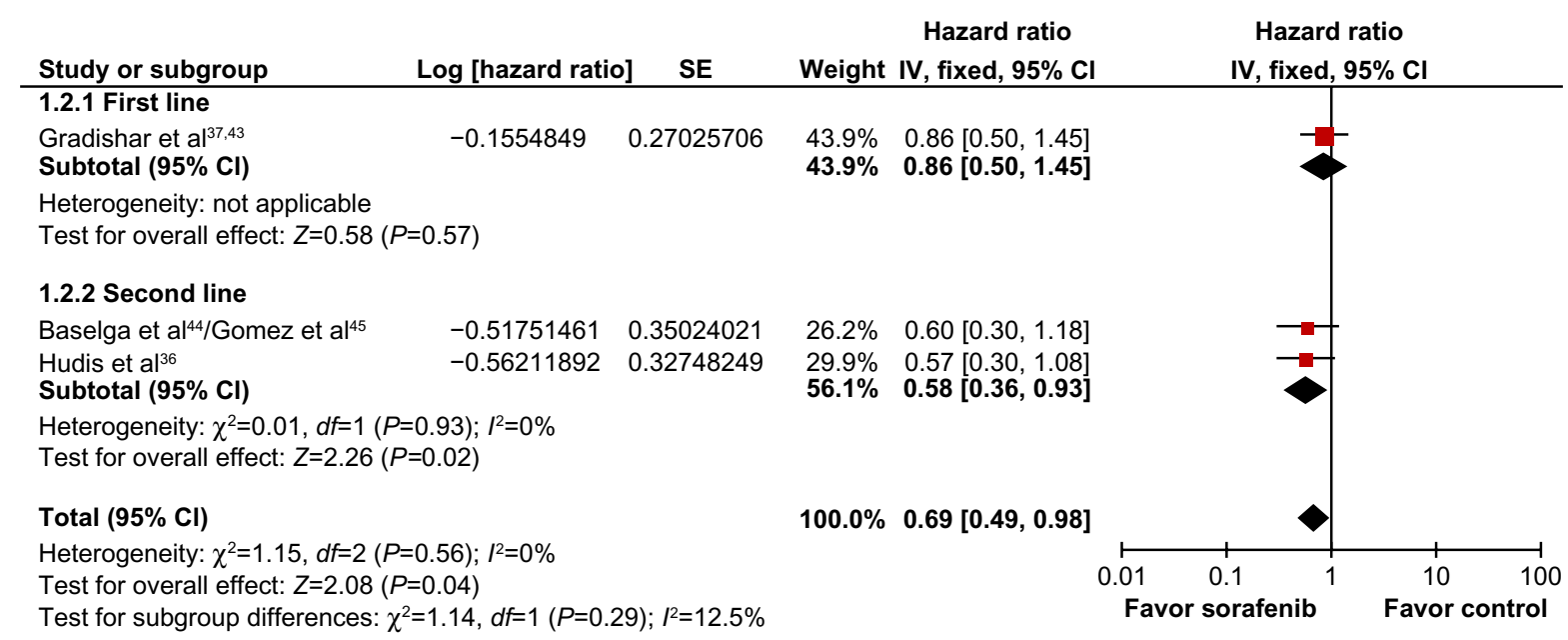

Figure 3 Comparative effect on progression-free survival of chemotherapy plus sorafenib versus chemotherapy alone (fixed-effect model analysis). Abbreviations: SE, standard error; IV, inverse variance; Cl, confidence interval; df, degrees of freedom. 
in patients without previous treatment. PFS was similar between the groups (HR $=1.25,95 \%$ CI 0.85-1.83).

\section{Chemotherapy with PARP inhibitor (iniparib)}

Two studies evaluated CT with PARP inhibitors (iniparib $5.6 \mathrm{mg} / \mathrm{kg}$; intravenous on days $1,4,8$, and 11 every 21 days) in patients previously treated ${ }^{19,48,49}$ (Table 2 ). A pooled analysis of the studies showed a higher response rate favoring the iniparib plus CT group (fixed effect, RR $=0.90,95 \%$ CI $0.80-0.10$; $P=0.05)$ with significant heterogeneity $\left(\chi^{2}=2.94, d f=1 ; P=0.09\right.$; $I^{2}=66 \%$ ). As planned, a random-effects model analysis was performed to better explore this heterogeneity: in this analysis, the response rate did not reach a statistically significant level (random effects, RR $=0.84,95 \%$ CI $0.64-1.11 ; P=0.23$ ).

PFS was higher in the group that received iniparib plus CT (fixed effect, HR $=0.75,95 \%$ CI 0.62-0.90; $P=0.002$; NNT $=3)$. There was moderate heterogeneity $\left(\chi^{2}=1.54\right.$, $d f=1 ; P=0.21 ; I^{2}=35 \%$ ) (Figure 4 ). A random-effects model analysis was performed, and PFS remained favorable to the $\mathrm{CT}$ plus iniparib group (random effects, $\mathrm{HR}=0.72,95 \% \mathrm{CI}$ $0.56-0.94 ; P=0.02$ ).

The meta-analysis of OS data favored the group that received iniparib plus CT (fixed effect, HR $=0.80$, 95\% CI $0.65-0.98 ; P=0.03)$ but with significant heterogeneity $\left(\chi^{2}=2.57, d f=1 ; P=0.11 ; I^{2}=61 \%\right)$ (Figure 5). The randomeffects model analysis for this end point did not reach a significant difference (random effects, $\mathrm{HR}=0.74,95 \% \mathrm{CI}$ $0.49-1.11 ; P=0.14)$. Hematologic and nonhematologic toxicities were similar between the groups.

\section{Discussion}

As a group, patients with TN tumors have a relatively poor outcome and cannot be treated with endocrine therapy or therapies targeted to human epidermal growth factor receptor type $2 .{ }^{50}$ Indeed, this group remains a poorly studied one: there are only a few studies designed specifically to evaluate the effect of CT in TNBC.
This systematic review aimed to evaluate the efficacy of different targeted therapies in TNBC. The results of the metaanalysis showed that these patients might benefit from some of these new therapies: there were significant benefits in PFS associated with Bev, Sor, and iniparib, regardless of the line of treatment; however, cetuximab results are inconclusive so far.

A possible effect of targeted therapies on OS could not be drawn from the published literature, as this end point was not consistently reported in most of the original trials for the TNBC population. The only feasible OS meta-analysis was the one derived from the studies that tested iniparib, in which results were heterogeneous and did not reach statistical significance in a random-effects model analysis. ${ }^{30}$ Historically, clinical studies in the advanced breast cancer setting have used PFS as the primary end point, ${ }^{51}$ but there is still controversy concerning whether it correlates with OS. ${ }^{52,53}$

In general, the toxicity reported in the studies was expected and not limiting. ${ }^{16,17,38-40}$ Bev plus CT was associated with higher rates of proteinuria, hypertension, neuropathy, and bleeding events; hand/foot skin reaction and mucositis were more common in patients who received Sor plus CT; neutropenia and rash were more frequent in patients who received cetuximab plus $\mathrm{CT}$.

Despite these encouraging results, many unsolved questions remain regarding targeted therapies combined with CT in TNBC patients. There are still no answers for some important points: which is the most suitable chemotherapy scheme for the association, which are the best molecular-targeted therapies, how to determine the ideal treatment sequence, and the real impact of using targeted therapy combined with CT in overall survival.

An important drawback of this study is that most of the data used in the meta-analysis came from subgroups that were not reported in the original publication and were obtained from secondary sources. Also limiting is the lack of important data from many of the included trials. Ideally, new trials should be performed in this specific population, and trials performed with the general breast cancer population should plan and report separately the results for TNBC patients.

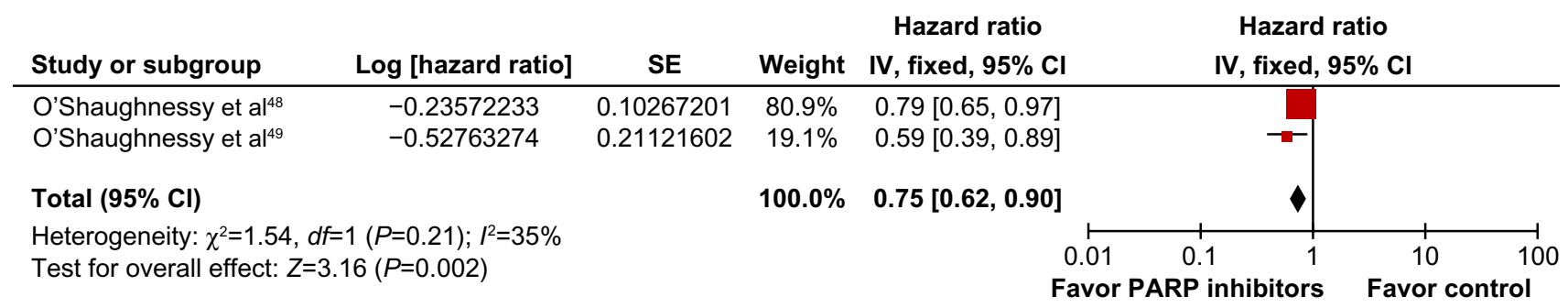

Figure 4 Comparative effect on progression-free survival of chemotherapy plus iniparib versus chemotherapy alone (fixed-effect model analysis).

Abbreviations: SE, standard error; IV, inverse variance; Cl, confidence interval; $d f$, degrees of freedom; PARP, poly(adenosine diphosphate-ribose) polymerase. 


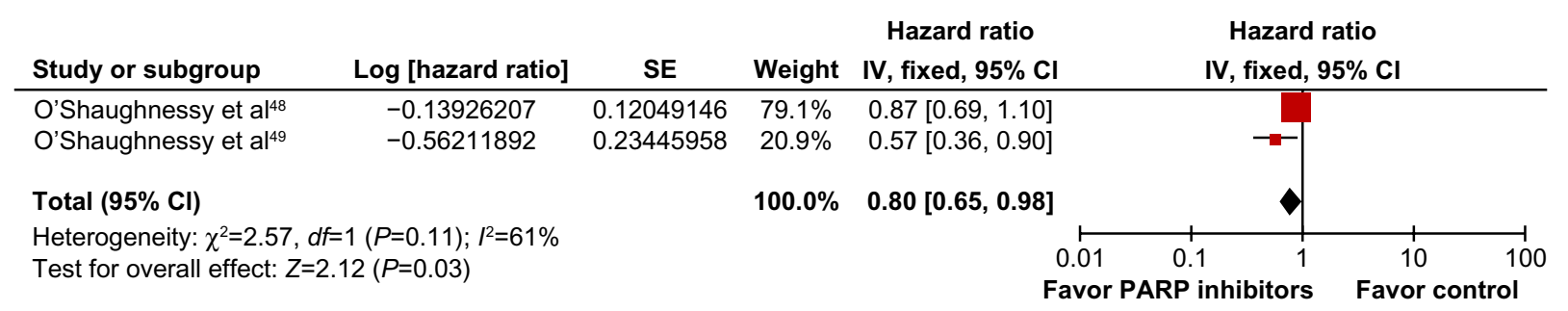

Figure 5 Comparative effect on overall survival of chemotherapy plus iniparib versus chemotherapy alone (fixed-effect model analysis).

Abbreviations: SE, standard error; IV, inverse variance; Cl, confidence interval; df, degrees of freedom; PARP, poly(adenosine diphosphate-ribose) polymerase.

Studies already published could also make a significant contribution to the understanding of this subject if an analysis was published with data from this subgroup.

\section{Conclusion}

Targeted therapy, when associated with conventional CT, demonstrated gain in PFS in patients with TNBC. The results concerning OS are still uncertain.

\section{Author contributions}

All authors of this research paper directly participated in the planning, execution, or analysis of the study. OC and LP conceived of the study, participated in its design and coordination, and helped to draft the manuscript. OC and TEAB carried out the data selection. All authors participated in the analysis. Also, all authors of this paper read and approved the final version submitted.

\section{Acknowledgments}

The authors wish to acknowledge Roche do Brasil, especially Valeria Clemente, Antonio Silva, and Elen Miúra, for support in the development of the study, and Christiane Bueno for the revision of the text.

\section{Disclosure}

The authors report no conflicts of interest in this work.

\section{References}

1. Baselga J, Segalla JG, Roché H, et al. Sorafenib in combination with capecitabine: an oral regimen for patients with HER2-negative locally advanced or metastatic breast cancer. J Clin Oncol. 2012;30(13): 1484-1491.

2. Carey LA, Dees EC, Sawyer L, et al. The triple negative paradox: primary tumor chemosensitivity of breast cancer subtypes. Clin Cancer Res. 2007;13(8):2329-2334.

3. Dent R, Trudeau M, Pritchard KI, et al. Triple-negative breast cancer: clinical features and patterns of recurrence. Clin Cancer Res. 2007; 13(15 Pt 1):4429-4434.

4. Haffty BG, Yang Q, Reiss M, et al. Locoregional relapse and distant metastasis in conservatively managed triple negative early-stage breast cancer. J Clin Oncol. 2006;24(36):5652-5657.

5. Harris LN, Broadwater G, Lin NU, et al. Molecular subtypes of breast cancer in relation to paclitaxel response and outcomes in women with metastatic disease: results from CALGB 9342. Breast Cancer Res. 2006;8(6):R66.
6. Morris GJ, Naidu S, Topham AK, et al. Differences in breast carcinoma characteristics in newly diagnosed African-American and Caucasian patients: a single-institution compilation compared with the National Cancer Institute's Surveillance, Epidemiology, and End Results database. Cancer. 2007;110(4):876-884.

7. Rakha EA, El-Sayed ME, Green AR, Lee AH, Robertson JF, Ellis IO. Prognostic markers in triple-negative breast cancer. Cancer. 2007;109(1):25-32.

8. Tischkowitz M, Brunet JS, Bégin LR, et al. Use of immunohistochemical markers can refine prognosis in triple negative breast cancer. $B M C$ Cancer. 2007;7:134.

9. Petrelli F, Cabiddu M, Ghilardi M, Barni S. Current data of targeted therapies for the treatment of triple-negative advanced breast cancer: empiricism or evidence-based? Expert Opin Investig Drugs. 2009;18(10):1467-1477.

10. Rydén L, Jirström K, Haglund M, Stål O, Fernö M. Epidermal growth factor receptor and vascular endothelial growth factor receptor 2 are specific biomarkers in triple-negative breast cancer. Results from a controlled randomized trial with long-term follow-up. Breast Cancer Res Treat. 2010;120(2):491-498.

11. Fornier M, Fumoleau P. The paradox of triple negative breast cancer: novel approaches to treatment. Breast J. 2012;18(1):41-51.

12. Kandel MJ, Stadler Z, Masciari S, et al, editors. Prevalence of BRCA1 mutations in triple negative breast cancer (BC). J Clin Oncol. 2006;24(18S):508

13. Turner NC, Reis-Filho JS. Basal-like breast cancer and the BRCA1 phenotype. Oncogene. 2006;25(43):5846-5853.

14. Elias AD. Triple-negative breast cancer: a short review. Am J Clin Oncol. 2010;33(6):637-645.

15. Bhattacharyya A, Ear US, Koller BH, Weichselbaum RR, Bishop DK. The breast cancer susceptibility gene BRCA1 is required for subnuclear assembly of Rad51 and survival following treatment with the DNA crosslinking agent cisplatin. J Biol Chem. 2000;275(31):23899-23903.

16. Miles D, Chan A, Romieu G, et al. Randomized, double-blind, placebocontrolled, phase III study of bevacizumab with docetaxel or docetaxel with placebo as first-line therapy for patients with locally recurrent or metastatic breast cancer (mBC): AVADO. J Clin Oncol. 2008;26(15S):LBA1011.

17. Miller K, Wang M, Gralow J, et al. Paclitaxel plus bevacizumab versus paclitaxel alone for metastatic breast cancer. $N$ Engl J Med. 2007;357(26):2666-2676.

18. O'Shaughnessy J, Weckstein DJ, Vukelja SJ, et al. Preliminary results of a randomized phase II study of weekly irinotecan/carboplatin with or without cetuximab in patients with metastatic breast cancer. Breast Cancer Res Treat. 2007;106 Suppl 1:S32.

19. O'Shaughnessy J, Schwartzberg LS, Danso MA, et al. A randomized phase III study of iniparib (BSI-201) in combination with gemcitabine/ carboplatin (G/C) in metastatic triple-negative breast cancer (TNBC). J Clin Oncol. 2011;29 Suppl:1007.

20. Hudis CA, Gianni L. Triple-negative breast cancer: an unmet medical need. Oncologist. 2011;16 Suppl 1:1-11.

21. Dickersin K, Scherer R, Lefebvre C. Identifying relevant studies for systematic reviews. BMJ. 1994;309(6964):1286-1291.

22. Clarke M, Oxman AD, editors. Cochrane Handbook for Systematic Reviews of Interventions. Version 4.1.1. Oxford: Cochrane Library; 2000. 
23. Castro AA, Clark OA, Atallah AN. Optimal search strategy for clinical trials in the Latin American and Caribbean Health Science Literature database (LILACS database): update. Sao Paulo Med J. 1999;117(3):138-139.

24. Egger M, Smith GD, Altman D. Systematic Reviews in Health Care: Meta-analysis in Context. London: BMJ Books; 2001.

25. Finn RS, Bengala C, Ibrahim N, et al. Phase II trial of dasatinib in triple-negative breast cancer: results of study CA180059. Cancer Res. 2009;69(2 Suppl 1):3118.

26. Parmar MK, Torri V, Stewart L. Extracting summary statistics to perform meta-analyses of the published literature for survival endpoints. Stat Med. 1998;17(24):2815-2834.

27. Higgins JP, Thompson SG, Deeks JJ, Altman DG. Measuring inconsistency in meta-analyses. BMJ. 2003;327(7414):557-560.

28. Yang K, Wang YJ, Chen XR, Chen HN. Effectiveness and safety of bevacizumab for unresectable non-small-cell lung cancer: a metaanalysis. Clin Drug Investig. 2010;30(4):229-241.

29. Deeks JJ, Higgins JPT, Altman DG. Analysing and presenting results. In: Higgins JPT, Green S, editors. Cochrane Handbook for Systematic Reviews of Interventions. Version 4.2.6. Chichester, UK: John Wiley \& Sons; 2006.

30. DerSimonian R, Laird N. Meta-analysis in clinical trials. Control Clin Trials. 1986;7(3):177-188.

31. Egger M, Davey Smith G, Schneider M, Minder C. Bias in meta-analysis detected by a simple, graphical test. BMJ. 1997;315(7109):629-634.

32. McQuay HJ, Moore RA. Using numerical results from systematic reviews in clinical practice. Ann Intern Med. 1997;126(9):712-720.

33. Smeeth L, Haines A, Ebrahim S. Numbers needed to treat derived from meta-analyses - sometimes informative, usually misleading. $B M J$. 1999;318(7197):1548-1551.

34. Altman DG, Deeks JJ. Meta-analysis, Simpson's paradox, and the number needed to treat. BMC Med Res Methodol. 2002;2:3.

35. Liberati A, Altman DG, Tetzlaff J, et al. The PRISMA statement for reporting systematic reviews and meta-analyses of studies that evaluate health care interventions: explanation and elaboration. Ann Intern Med. 2009;151(4):W65-W94.

36. Hudis C, Tauer KW, Hermann RC, et al. Sorafenib (SOR) plus chemotherapy (CRx) for patients (pts) with advanced (adv) breast cancer (BC) previously treated with bevacizumab (BEV). J Clin Oncol. 2011; 29 Suppl:1009.

37. Gradishar W. A double-blind, randomized phase $2 \mathrm{~b}$ study evaluating the efficacy and safety of sorafenib compared to placebo when administered in combination with paclitaxel in patients with locally recurrent of metastatic breast cancer. Poster presented at: Annual San Antonio Breast Cancer Symposium; December 9-13, 2009; San Antonio, TX.

38. O'Shaughnessy J, Dieras V, Glaspy J, et al. Comparison of subgroup analyses of PFS from three phase III studies of bevacizumab in combination with chemotherapy in patients with HER2-negative metastatic breast cancer (MBC). Cancer Res. 2009;69(24 Suppl 3):207.

39. Robert NJ. RIBBON-1: randomized, double-blind, placebo-controlled, phase III trial of chemotherapy with or without bevacizumab (B) for first-line treatment of HER2-negative locally recurrent or metastatic breast cancer (MBC). J Clin Oncol. 2009;27(Suppl 15):1005.

40. Robert NJ, Diéras V, Glaspy J, et al. RIBBON-1: randomized, doubleblind, placebo-controlled, phase III trial of chemotherapy with or without bevacizumab for first-line treatment of human epidermal growth factor receptor 2-negative, locally recurrent or metastatic breast cancer. J Clin Oncol. 2011;29(10):1252-1260.

41. Brufsky A, Valero V, Tiangco B, et al. Impact of bevacizumab (BEV) on efficacy of second-line chemotherapy (CT) for triple-negative breast cancer (TNBC): analysis of RIBBON-2. J Clin Oncol. 2011;29 Suppl:1010.

42. Brufsky A, Valero V, Tiangco B, et al. Second-line bevacizumabcontaining therapy in patients with triple-negative breast cancer: subgroup analysis of the RIBBON-2 trial. Breast Cancer Res Treat. 2012;133(3):1067-1075.
43. Gradishar WJ, Kaklamani V, Sahoo TP, et al. A double-blind, randomised, placebo-controlled, phase $2 \mathrm{~b}$ study evaluating sorafenib in combination with paclitaxel as a first-line therapy in patients with HER2-negative advanced breast cancer. Eur $J$ Cancer. 2013;49(2):312-322.

44. Baselga J, Roche H, Costa F, et al. SOLTI-0701: A multinational doubleblind, randomized phase $2 \mathrm{~b}$ study evaluating the efficacy and safety of sorafenib compared to placebo when administered in combination with capecitabine in patients with locally advanced or metastatic breast cancer. Cancer Res. 2009;69(24 Suppl 3):45.

45. Gomez P, Roche H, Costa F, et al. Overall survival data from SOLTI0701: a multinational, double-blind, placebo-controlled, randomized phase $2 \mathrm{~b}$ study evaluating the oral combination of sorafenib and capecitabine in patients with locally advanced or metastatic HER2-negative breast cancer. Cancer Res. 2010;70(24 Suppl 2):P2-16-01.

46. Baselga J, Stemmer S, Pego A, et al. Cetuximab + cisplatin in estrogen receptor-negative, progesterone receptor-negative, HER2-negative (triple-negative) metastatic breast cancer: results of the randomized phase II BALI-1 trial. Cancer Res. 2010;70(24 Suppl 2):PD01-01.

47. Finn RS, Press MF, Dering J, et al. Estrogen receptor, progesterone receptor, human epidermal growth factor receptor 2 (HER2), and epidermal growth factor receptor expression and benefit from lapatinib in a randomized trial of paclitaxel with lapatinib or placebo as first-line treatment in HER2-negative or unknown metastatic breast cancer. J Clin Oncol. 2009;27(24):3908-3915.

48. O'Shaughnessy J, Osborne C, Pippen JE, et al. Iniparib plus chemotherapy in metastatic triple-negative breast cancer. $N$ Engl $J$ Med. 2011;364(3):205-214.

49. O'Shaughnessy JA, Osborne C, Pippen J, et al. Efficacy of BSI-201, a poly (ADP-ribose) polymerase-1 (PARP1) inhibitor, in combination with gemcitabine/carboplatin $(\mathrm{G} / \mathrm{C})$ in patients with metastatic triplenegative breast cancer: results of a randomized phase II trial. J Clin Oncol. 2009;27(Suppl 18):03

50. Foulkes WD, Smith IE, Reis-Filho JS. Triple-negative breast cancer. N Engl J Med. 2010;363(20):1938-1948.

51. Saad ED, Katz A, Hoff PM, Buyse M. Progression-free survival as surrogate and as true end point: insights from the breast and colorectal cancer literature. Ann Oncol. 2010;21(1):7-12.

52. Hackshaw A, Knight A, Barrett-Lee P, Leonard R. Surrogate markers and survival in women receiving first-line combination anthracycline chemotherapy for advanced breast cancer. Br J Cancer. 2005;93(11): 1215-1221.

53. Miksad RA, Zietemann V, Gothe R, et al. Progression-free survival as a surrogate endpoint in advanced breast cancer. Int J Technol Assess Health Care. 2008;24(4):371-383.

54. Chia JW. Triple-negative metastatic/recurrent breast cancer: Treatment with paclitaxel/carboplatin combination chemotherapy. Journal of Clinical Oncology. 2007;25(18S):1086.

55. Curigliano G, Pivot X, Cortes J, et al. A randomized phase II study of sunitinib vs. standard of care for patients with previously treated advanced triple-negative breast cancer. Cancer Res. 2010;70(24 Suppl):Abstract nr P6-12-02.

56. Berry DA, Cirrincione C, Henderson IC, Citron ML, Budman DR, Goldstein LJ, et al. Estrogen-receptor status and outcomes of modern chemotherapy for patients with node-positive breast cancer. JAMA. 2006;295(14):1658-1667.

57. Gluz O, Nitz UA, Harbeck N, Ting E, Kates R, Herr A, et al. Triplenegative high-risk breast cancer derives particular benefit from dose intensification of adjuvant chemotherapy: results of WSG AM-01 trial. Ann Oncol. 2008;19(5):861-870.

58. Rodenhuis S, Bontenbal M, van Hoesel QG, Smit WM, Nooij MA, Voest EE, et al. Efficacy of high-dose alkylating chemotherapy in HER2/ neu-negative breast cancer. Ann Oncol. 2006;17(4):588-596.

59. Silver DP, Richardson AL, Eklund AC, Wang ZC, Szallasi Z, Li Q, et al. Efficacy of neoadjuvant Cisplatin in triple-negative breast cancer. J Clin Oncol. 2010;28(7):1145-1153. 
60. Bonnefoi H, Potti A, Delorenzi M, Mauriac L, Campone M, Tubiana-Hulin $\mathrm{M}$, et al. Validation of gene signatures that predict the response of breast cancer to neoadjuvant chemotherapy: a substudy of the EORTC 10994/BIG 00-01 clinical trial. Lancet Oncol. 2007;8(12):1071-1078.

61. Leone JP, Guardiola V, Venkatraman A, Pegram MD, Welsh C, Silva O, et al. Neoadjuvant platinum-based chemotherapy (CT) for triple-negative locally advanced breast cancer (LABC): Retrospective analysis of 125 patients. J Clin Oncol. 2009;27:15s (suppl; abstr 625).

62. Torrisi R, Balduzzi A, Ghisini R, Rocca A, Bottiglieri L, Giovanardi F, et al. Tailored preoperative treatment of locally advanced triple negative (hormone receptor negative and HER2 negative) breast cancer with epirubicin, cisplatin, and infusional fluorouracil followed by weekly paclitaxel. Cancer Chemother Pharmacol. 2008;62(4):667-672.

63. Ryan PD, Tung NM, Isakoff SJ, Golshan M, Richardson A, Corben AD, et al. Neoadjuvant cisplatin and bevacizumab in triple negative breast cancer (TNBC): Safety and efficacy. J Clin Oncol. 2009;27:15s (suppl; abstr 551).

64. Frasci G, Comella P, Rinaldo M, Iodice G, Di Bonito M, D'Aiuto M, et al. Preoperative weekly cisplatin-epirubicin-paclitaxel with G-CSF support in triple-negative large operable breast cancer. Ann Oncol. 2009;20(7):1185-1192.

65. Finn RS, Bengala C, Ibrahim N, et al. Phase II trial of dasatinib in triple-negative breast cancer: results of study CA180059. Cancer Res. 2009;69(2 Suppl):Abstract nr 3118.

66. Wang $\mathrm{Z}, \mathrm{Hu} \mathrm{X}$, Chen $\mathrm{L}$, et al. Efficacy of gemcitabine and cisplatin (GP) as first-line combination therapy in patients with triple-negative metastatic breast cancer: Preliminary results report of a phase II trial. J Clin Oncol. 2010;28:138s (suppl; abstr 1100).

67. Citron ML, Berry DA, Cirrincione C, Hudis C, Winer EP, Gradishar WJ, et al. Randomized trial of dose-dense versus conventionally scheduled and sequential versus concurrent combination chemotherapy as postoperative adjuvant treatment of node-positive primary breast cancer: first report of Intergroup Trial C9741/Cancer and Leukemia Group B Trial 9741. J Clin Oncol. 2003;21(8):1431-1439.
68. Garber J, Richardson A, Harris L, et al. Neo- adjuvant cisplatin (CDDP) in triple-negative breast cancer (BC). Breast Cancer Res Treat. 2006;100:S149 [abstract 3074].

69. Byrski T, Gronwald J, Huzarski T, et al. Response to neo-adjuvant chemotherapy in women with BRCA1- positive breast cancers. Breast Cancer Res Treat. 2008;108:289-296.

70. von Minckwitz G, Raab G, Caputo A, Schutte M, Hilfrich J, Blohmer JU, et al. Doxorubicin with cyclophosphamide followed by docetaxel every 21 days compared with doxorubicin and docetaxel every 14 days as preoperative treatment in operable breast cancer: the GEPARDUO study of the German Breast Group. J Clin Oncol. 2005;23(12):2676-2685.

71. Carey LA, Rugo HS, Marcom PK, et al. TBCRC 001: EGFR inhibition with cetuximab added to carboplatin in metastatic triple-negative (basallike) breast cancer. J Clin Oncol. 2008;26: (Abstr 1009, presented at ASCO Annual Meeting 2008).

72. Bhattacharyya GS, Basu S, Agarwal V, et al. Single institute phase II study of weekly cisplatinum and metronomic dosing of cyclophosphamide and methotrexate in second line metastatic breast cancer triplenegative. Eur J Cancer. 2009;7:18 (Abstr 41LBA, presented at ECCO 15-ESMO 34 2009).

73. Rugo HS. Ixabepilone plus capecitabine vs. capecitabine in patients with triple negative tumors: a pooled analysis of patients from two large phase III clinical studies. Cancer Res. 2009;69(2 Suppl):Abstract nr 3057.

74. Gelmon K, Dent R, Mackey JR, Laing K, McLeod D, Verma S. Targeting triple-negative breast cancer: optimising therapeutic outcomes. Ann Oncol. 2012;23(9):2223-2234.

75. Rodler E, Korde L, Gralow J. Current treatment options in triple negative breast cancer. Breast Dis. 2010;32(1-2):99-122.

\section{Core Evidence}

\section{Publish your work in this journal}

Core Evidence is an international, peer-reviewed open-access journal evaluating the evidence underlying the potential place in therapy of drugs throughout their development lifecycle from preclinical to postlaunch. The focus of each review is to evaluate the case for a new drug or class in outcome terms in specific indications and patient groups

\section{Dovepress}

The manuscript management system is completely online and includes a very quick and fair peer-review system, which is all easy to use. Visit http://www.dovepress.com/testimonials.php to read real quotes from published authors. 